\title{
Improvement of the Osmotic Fragility (OF) Test in a Thalassemia 1 Screening for HIV-1 Infected Patients by The New Cutoff Values of $\mathrm{MCV}$ and $\mathrm{MCH}$
}

\author{
Sarayot Rareongjai, Ph.D. ${ }^{1}$, Sitthichai Panyasai, Ph.D. ${ }^{1}$, Santipap Sooncharoen, B.Sc. ${ }^{1}$, \\ Soraya Mol-ar, B.Sc. ${ }^{1}$, Orathai Pongtussanahem, B.Sc. ${ }^{2}$ \\ ${ }^{1}$ School of Allied Health Sciences, University of Phayao, Mueang, Phayao 56000, Thailand. \\ ¿Laboratory of Medical Technology, Dok Kham Tai Hospital, Dok Kham Tai, Phayao 56120, Thailand. \\ Received 20 August 2018 • Revised 3 November 2018 • Accepted 14 November 2018 • Published online 14 December 2018
}

\section{Abstract:}

Objective: To evaluate the efficiencies of the standard $a$ thalassemia screening regimen in human immunodeficiency virus (HIV) infected patients and improve the efficiencies of this screening regimen using new cutoff values.

Material and Methods: A screening process using the osmotic fragility (OF) test, the old cutoff values of mean corpuscular volume $(\mathrm{MCV})$ and mean corpuscular hemoglobin $(\mathrm{MCH})$ at $<80 \mathrm{fL}$ and $<22 \mathrm{pg}$, and the new cutoff values at $<87$ $\mathrm{fL}$ and $<29 \mathrm{pg}$ was performed in 300 HIV infected patients. After which, a genetic study was performed to detect common a thalassemia 1 genes deletions composed of Southeast Asian and THAl deletions and also for hemoglobin constant spring and hemoglobin Pakse mutations for a thalassemia 2 carriers. Screening efficiency was estimated by sensitivity, specificity, positive predictive value (PPV) and negative predictive value (NPV).

Results: Sensitivity, specificity, PPV, and NPV of the original regimen for thalassemia screening in HIV infected patients were at $50.0 \%, 95.0 \%, 39.0 \%$ and $96.8 \%$, respectively, demonstrating a high false positivity in HIV-1 infected populations. Therefore, new cutoff values for $\mathrm{MCV}$ and $\mathrm{MCH}$ were proposed at $<87 \mathrm{fL}$ and $<29 \mathrm{pg}$, due to the highest value found in a thalassemia 1 carriers with HIV-1 infection. These new cutoff values showed higher sensitivity, specificity, PPV, and NPV at $100.092 .6 \%, 46.2 \%$, and 100.0\%, respectively, and thus enhanced thalassemia screening efficiency in HIV-1 infected patients.

Conclusion: Incorporation of the OF test and the new cutoff values for $\mathrm{MCV}$ and $\mathrm{MCH}$ improve the efficiencies of a thalassemia 1 screening in HIV-1 infected patients. This helps reduce the cost of confirming positive test results in a thalassemia screening.

Keywords: $\alpha$ thalassemia, HIV-1, MCH, MCV, OF test

Contact: Sarayot Rareongjai, Ph.D.

School of Allied Health Sciences, University of Phayao, Mueang, Phayao

56000, Thailand.

E-mail: Gangkku@hotmail.com
J Health Sci Med Res 2019;37(1):25-34 doi: 10.31584/jhsmr.201935 www.jhsmr.org 


\section{Introduction}

Thalassemia is a fairly common inherited disorder in Thailand. ${ }^{1}$ It is caused by abnormal globin protein synthesis. ${ }^{2}$ One of the most severe thalassemia syndromes is hemoglobin $(\mathrm{Hb})$ Bart's hydrops fetalis, which is caused by the deletion of all the a globin genes. ${ }^{3}$ Fetuses with this disease are stillborn while the mothers frequently exhibit preeclampsia, and polyhydramnios. ${ }^{4}$ To reduce this condition, screening for the a thalassemia 1 gene in couples was implemented. ${ }^{5}$

Two methods are used for $\alpha$ thalassemia 1 screening, the osmotic fragility (OF) test, and the mean corpuscular volume (MCV) and mean corpuscular hemoglobin $(\mathrm{MCH})$. The principle of these two-screening methods is based on the reduction of $\mathrm{Hb}$ content in red blood cells, which leads to a disproportion between red blood cell volume and $\mathrm{Hb}$ concentration inside the cells, resulting in a positive OF test, and the reduction of MCV and $\mathrm{MCH}$ values. ${ }^{6}$ Patients who have positive results for any screening test should undergo genetic testing for confirmation. This process is very expensive and less efficient than the screening processes. ${ }^{7}$ The efficiency of thalassemia screening is represented by sensitivity, specificity, positive predictive values (PPV), and negative predictive values (NPV). These were 100.0, 87.1, 84.5 and $100.0 \%$ for the OF test and 92.9, 83.9, 37.9 and $99.1 \%$ for MCV and $\mathrm{MCH}$.

There are high numbers of human immunodeficiency virus (HIV) infected couples in antenatal care in Thailand, as a result of the reduced rate of HIV antenatal transmission to $1.9 \%$ in $2016,,^{9,10}$ due to the improved efficiency of the antiviral drugs. All HIV infected couples in this program also underwent normal $\alpha$ thalassemia screening. However, recent evidence indicates changes in the hematological parameters of HIV-1 infected patients. The major effect caused by antiretroviral drugs is that some of them influence bone marrow suppression via blocking of nucleic acid synthesis which leads to macrocytosis in HIV infected patients. ${ }^{11-13}$ The changes of hematological parameters include $\mathrm{Hb}$ levels, $\mathrm{MCV}$ and $\mathrm{MCH}^{11}$ caused by the reduction of $\mathrm{Hb}$ in red blood cells, the reduction of red blood volume and the impairment of $\mathrm{Hb}$ and blood cell volume. In addition, other evidence also suggesting a high rigidity of red blood cells was observed in patients with HIV infection. ${ }^{14}$ These changes may interfere with thalassemia screening by OF test, MCV and $\mathrm{MCH}$, and may result in many patients requiring confirmation testing by deoxyribonucleic acid (DNA) analyses. However, these changes affecting the efficiency of each screening method have not been investigated.

Therefore, the efficiencies of the test were analysed with the aim of enhancing and improving $\alpha$ thalassemia 1 screening in $\mathrm{HIV}-1$ infected patients in order to reduce the number of the false positive results and also the costs of confirmatory analyses.

\section{Material and Methods}

\section{HIV infected patients}

This was an experimental research study. Subjects were $300 \mathrm{HIV}-1$ infected patients. Two milliliters of blood were collected from patients during a 1-year follow-up of normal monitoring from June 2015-April 2016. Clinical data including drugs used in the treatment and period of HIV infection were collected. Patients with mild anemia and other signs of iron deficiency were excluded from the study.

The study was approved by the Human Research Ethics Committee of the University of Phayao in January 2015 (No. 3/001/59).

\section{$\alpha$ thalassemia screening}

A blood sample collected from each candidate was used to screen for a thalassemia 1 by OF test as previously described, and $\mathrm{MCV}$ and $\mathrm{MCH}$ testing using 
complete blood count (CBC) by an automated hematology analyser (Mindry BC-5180). Then, the MCV and $\mathrm{MCH}$ of patients were interpreted using standard cutoff values at $80 \mathrm{fL}$ and $27 \mathrm{pg}$ respectively, in order to indicate the likelihood of $\alpha$ thalassemia 1 carriers. Samples with lower $\mathrm{MCV}$ and $\mathrm{MCH}$ than the cutoff were defined as screening positive, while scores higher, than the cutoff were defined as negative for $\alpha$ thalassemia 1 . In addition, in the all patients it was confirmed that they were without evidence of the $\beta$ thalassemia traits by a normal level of $\mathrm{Hb} A_{2}$.

\section{DNA analyses of $\alpha$ thalassemia carriers}

Two common a thalassemia 1 deletions in Thailand: Southeast Asian (SEA) and THAl deletions, which were analysed in all the patients' DNA as described below. DNA was extracted from $500 \mu \mathrm{L}$ of buffy coat using the chloroform extraction method. The DNA was then amplified by 6 specific a globin gene primers using a multiplex gap polymerase chain reaction, following the method described by Sae-ung et al. ${ }^{15}$ Three specific amplification products from these primer pairs were used to indicate the presence of $\alpha$ thalassemia 1 deletions including 660 bps, 480 bps and 380 bps for SEA deletion, THAI deletion and the control amplicon, respectively. All amplicons were analysed in parallel with positive control for SEA and THAI deletions.

To rule out a change of hematological parameters and to confirm a positive result of OF test from other $a$ thalassemia carriers, 2 severe a thalassemia 2 genes that show a correlation with OF test positive were also detected as $\mathrm{Hb}$ Pakse (HbPS) and Hb Constant Spring (HbCS). These 2 genes were identified by a multiplex polymerase chain reaction developed by Fucharoen et al. ${ }^{16}$ Products of 253 and 183 bps indicated aPS and aCS respectively. The result of this amplification was also interpreted in parallel with positive control for $\mathrm{HbPS}$ and $\mathrm{HbCS}$.

\section{Defining of appropriate hematological parameter} for $\alpha$ thalassemia screening in HIV-1 infected patients

The data of each subject were collected: age, sex, hematological parameters including $\mathrm{Hb}$, Hct, RBC, MCV, $\mathrm{MCH}$ and red cell distribution width (RDW). All data were analyzed for identify differentiation in the sample group that might affect research results, especially the changes of hematological data that cause differences in age or sex. The parameters without of any effect from these factors will be used as tools for a thalassemia 1 screening. The differences of each hematological parameter were compared between males and females and in 5 different age groups using independent sample t-test and Mann Whitney $U$ test. The parameters given a $p$-value of more than 0.050 were used in the next defining process.

After that the effect of hematological parameters on the OF test result were also analysed using the independent sample t-test and Kruskal-Wallis one-way Analysis of Variance (ANOVA). In addition, correlations between these parameters and $\alpha$ thalassemia 1 deletion were analysed using Spearman's rank correlation coefficient with a confidence interval $(\mathrm{Cl})$ at 95\%.

\section{Efficiency of $\alpha$ thalassemia screening methods}

To evaluate the efficiency of the OF test in a thalassemia 1 screening, all samples were classified into 4 groups: (1) true positive, a group with positive results for any screening test that carried one $\alpha$ thalassemia 1 deletion, (2) false positive, a group with positive results for any screening test but did not carry any abnormal a thalassemia 1 deletion, (3) true negative, a group with negative results for any screening test that did not carry the $\alpha$ thalassemia 1 deletion and (4) false negative which presented negative results for any screening test but contained one $\alpha$ thalassemia 1 deletion. The efficiency for screening tests was assessed using sensitivity, specificity, PPV and NPV by the number of patients in each group. 


\section{Results}

The suitable hematological parameters for $\alpha$

\section{thalassemia 1 screening}

The hematological parameters of each participant were analysed to identify a suitable parameter for $\alpha$ Thalassemia 1 screening. Findings demonstrated an almost equal ratio between male and female patients: 121 (40.3\%) male and 178 (59.3\%) female. Average ages of males and females were 46.6 (45.4-47.8) and 45.3 (44.1-46.4) respectively. Three factors of hematological data differed between the sex groups: Hb, Hct and RBC (Table 1).
Candidates were classified into 5 groups using age: $20-29,30-39,40-49,50-59$, and $\geq 60$. Most were in the 40-49 age group, 182 subjects (60.6\%). Interestingly, 3 hematological factors including $\mathrm{Hb}$, Hct and RBC tended to decrease in higher age groups. In contrast, $\mathrm{MCV}$ and $\mathrm{MCH}$ showed an increasing trend in higher age groups (Table 2). These analyses suggested that MCV and $\mathrm{MCH}$ were not statistically different between age and sex of study groups, and that they could be used as the a thalassemia screening markers for the patients.

Table 1 The number and the hematological data of human immunodeficiency virus infected samples classified by sex

\begin{tabular}{|c|c|c|c|c|c|c|c|c|}
\hline Sex & Number (\%) & $\begin{array}{l}\text { Age } \\
\text { Mean } \pm \text { S.D. }\end{array}$ & $\begin{array}{l}\mathrm{Hb}(\mathrm{g} / \mathrm{dL}) \\
\text { Mean } \pm S . D .\end{array}$ & $\begin{array}{l}\text { Het }(g \%) \\
\text { Mean } \pm \text { S.D. }\end{array}$ & $\begin{array}{l}\text { RBC }\left(\times 10^{6} / \mathrm{uL}\right) \\
\text { Mean } \pm S . D .\end{array}$ & $\begin{array}{l}\text { MCV (fL) } \\
\text { Mean } \pm S . D .\end{array}$ & $\begin{array}{l}\text { MCH (pg) } \\
\text { Mean } \pm \text { S.D. }\end{array}$ & $\begin{array}{l}\text { RDW (\%) } \\
\text { Mean } \pm \text { S.D. }\end{array}$ \\
\hline Male & $121(40.3)$ & $46.6 \pm 6.4$ & $13.6 \pm 1.59$ & $39.8 \pm 4,41$ & $3.9 \pm 0.73$ & $102.7 \pm 14.8$ & $35.1 \pm 6.3$ & $13.6 \pm 1.7$ \\
\hline Female & 178 (59.3) & $45.3 \pm 7.7$ & $12.3 \pm 1.28$ & $36.3 \pm 3.64$ & $3.6 \pm 0.68$ & $103.0 \pm 15.4$ & $34.8 \pm 6.4$ & $13.3 \pm 1.2$ \\
\hline & & p-value & $<0.0001^{1}$ & $<0.0001^{2}$ & $<0.0001^{2}$ & $0.662^{2}$ & $0.810^{2}$ & $0.088^{2}$ \\
\hline
\end{tabular}

${ }^{1} p$-value from independent sample t-test analyses, ${ }^{2} p$-value from Mann Whitney $U$ test

$\mathrm{Hb}=$ hemoglobin, $\mathrm{Hct}=$ hematocrit, $\mathrm{RBC}=$ red blood cell count, $\mathrm{MCV}=$ mean corpuscular volume, $\mathrm{MCH}=$ mean corpuscular hemoglobin,

RDW=red blood cell distribution width, S.D.=standard deviation

Table 2 Mean of the hematological data of 300 human immunodeficiency virus infected patients classified by age

\begin{tabular}{|c|c|c|c|c|c|c|c|c|c|}
\hline $\begin{array}{l}\text { Age } \\
\text { (years) }\end{array}$ & $\begin{array}{l}\text { Male } \\
(\%)\end{array}$ & $\begin{array}{l}\text { Female } \\
(\%)\end{array}$ & $\begin{array}{l}\text { Total } \\
(\%)\end{array}$ & $\begin{array}{l}\mathrm{Hb}(\mathrm{g} / \mathrm{dL}) \\
\text { MeantS.D. }\end{array}$ & $\begin{array}{l}\text { Het }(g \%) \\
\text { Mean } \pm S . D .\end{array}$ & $\begin{array}{l}\text { RBC }\left(\times 10^{6} / \mathrm{UL}\right) \\
\text { Mean } \pm \text { S.D. }\end{array}$ & 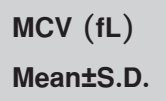 & $\begin{array}{l}\text { MCH (pg) } \\
\text { Mean士S.D. }\end{array}$ & $\begin{array}{l}\text { RDW (\%) } \\
\text { Mean } \pm S . D\end{array}$ \\
\hline 20-29 & $3(2.5)$ & $5(2.8)$ & $8(2.6)$ & $12.1 \pm 1.0$ & $37.6 \pm 3.5$ & $4.0 \pm 1.2$ & $100.6 \pm 22.5$ & $34.4 \pm 8.8$ & $13.5 \pm 1.6$ \\
\hline $30-39$ & $8(6.6)$ & 24 (13.5) & 32 (10.6) & $13.1 \pm 1.5$ & $38.8 \pm 4.8$ & $4.0 \pm 0.7$ & $99.0 \pm 13.9$ & $33.6 \pm 5.5$ & $13.6 \pm 1.3$ \\
\hline $40-49$ & $73(59.8)$ & 109 (61.2) & $182(60.6)$ & $12.7 \pm 1.5$ & $37.3 \pm 4.2$ & $3.7 \pm 0.6$ & $103.1 \pm 14.9$ & $35.2 \pm 6.1$ & $13.5 \pm 1.6$ \\
\hline 50-59 & 34 (27.9) & $32(18.0)$ & $66(22.0)$ & $13.0 \pm 1.5$ & $38.2 \pm 4.3$ & $3.8 \pm 0.7$ & $103.0 \pm 15.9$ & $34.4 \pm 7.4$ & $13.4 \pm 1.1$ \\
\hline \multirow[t]{2}{*}{$\geq 60$} & $4(3.3)$ & $8(4.5)$ & $12(4.0)$ & $13.1 \pm 1.7$ & $38.0 \pm 4.8$ & $3.5 \pm 0.6$ & $109.9 \pm 10.1$ & $38.1 \pm 3.9$ & $13.2 \pm 0.7$ \\
\hline & & & $\mathrm{p}$-value & $0.433^{1}$ & $0.377^{2}$ & $0.197^{2}$ & $0.167^{2}$ & $0.119^{2}$ & $0.584^{2}$ \\
\hline
\end{tabular}

${ }^{1} p$-value from ANOVA analyses ${ }^{2} \mathrm{p}$-value from Kruskal-Wallis test

$\mathrm{Hb}=$ hemoglobin, $\mathrm{Hct}=$ hematocrit, $\mathrm{RBC}=$ red blood cell count, $\mathrm{MCV}=$ mean corpuscular volume, $\mathrm{MCH}=$ mean corpuscular hemoglobin, $\mathrm{RDW}=$ red blood cell distribution width, S.D.=standard deviation 
Low efficiency of OF test in a thalassemia 1 screening in HIV-1 infected patients

Results indicated a low efficiency of the OF test in the detection of a thalassemia carriers in HIV infected patients. The parameters: sensitivity, specificity, PPV and NPV of the OF test were $100.0 \%, 66.6 \%, 16.0 \%$ and $100.0 \%$, respectively (Table 3 ). Therefore, it probably suggested that high false positive values occurred while utilizing the OF test as a screening method for a thalassemia 1 carriers in HIV-1 infected patients, leading to an increased cost of DNA analysis as the confirmation test. This result might be reflected in a change in hematologic features in HIV-1 infected patients. Hematological data of HIV infected patients as OF positive and OF negative were compared to define the differences between these 2 groups.

Nevertheless, only 3 hematological parameters, namely $\mathrm{Hb}, \mathrm{MCV}$, and $\mathrm{MCH}$ showed mild correlations with a thalassemia 1, indicated by the spearman $r$ at 0.268 , 0.304 , and 0.309 with $\mathrm{p}$-values of $5.8 \times 10^{-5}, 7.9 \times 10^{-12}$ and $9.9 \times 10^{-11}$ respectively. As previously mentioned, $\mathrm{Hb}$ could vary due to differences of age and sex. Only 2 parameters, $\mathrm{MCV}$ and $\mathrm{MCH}$, were used in the further study as an a thalassemia 1 screening tool in HIV-1 infected patients.

\section{Improvement of $\alpha$ thalassemia 1 screening in HIV-} 1 infected patients by the new cutoff of MCV and $\mathrm{MCH}$

Another previous method used for a thalassemia 1 screening in Thailand involves the cutoff values of MCV and $\mathrm{MCH}$ at $80 \mathrm{fL}$ and $27 \mathrm{pg}$ respectively. However, HIV-1 infected patients always show increasing MCV and $\mathrm{MCH}$, and this may interfere with the screening result. We demonstrated the efficiency of $\alpha$ thalassemia 1 screening using MCV <80 fL in HIV-1 infected patients in sensitivity, specificity, PPV and NPV, which were 50.0\%, 94.7\%, $37.5 \%$, and $96.7 \%$, respectively. Similarly, the efficiency of $\alpha$ thalassemia 1 screening using $\mathrm{MCH}<27 \mathrm{pg}$ in sensitivity, specificity, PPV and NPV were 66.7\%, 91.5\%, 33.3\%, and $97.7 \%$, respectively. It was demonstrated that using $\mathrm{MCV}$ and $\mathrm{MCH}$ for $\alpha$ thalassemia 1 screening helps improve specificity and PPV, but lowers the sensitivity and NPV of these screening tools. It is suggested that the HIV-1 infected patients may require a new specific cutoff for $\mathrm{MCV}$ and $\mathrm{MCH}$ in $\alpha$ thalassemia 1 screening. An investigation was carried out in order to determine the efficiency of the new cutoff compared with the old cutoff.

The new cutoff was analysed by comparing hematological data between patients with and without the a thalassemia 1 gene. $\mathrm{MCV}$ and $\mathrm{MCH}$ between patients with and without $\alpha$ thalassemia 1 were analyzed. We found

Table 3 Frequencies of $\alpha$ thalassemia gene and OF screening efficiency in HIV -1 infected patients

\begin{tabular}{|c|c|c|c|c|c|c|c|c|c|}
\hline \multirow{2}{*}{ Test } & \multirow{2}{*}{ Results } & \multicolumn{5}{|c|}{$\alpha$ thalassemia genes } & \multirow{2}{*}{ Total } & \multicolumn{2}{|c|}{ Screening efficacies } \\
\hline & & Negative & SEA & Thai & CS & PS & & Sensitivity & $100.0 \%(81.4-100.0 \%)$ \\
\hline \multirow[t]{2}{*}{ OF } & Negative & 169 & 0 & 0 & 19 & 0 & 188 & Specificity & $66.7 \%(60.8-72.1 \%)$ \\
\hline & Positive & 84 & 17 & 1 & 10 & 0 & 112 & PPV & $16.1 \%(13.9-18.4 \%)$ \\
\hline Total & & 253 & 17 & 1 & 29 & 0 & 300 & NPV & $100.0 \%$ \\
\hline
\end{tabular}

$\mathrm{OF}=$ osmotic fragility test, $\mathrm{SEA}=$ southeast asian, $\mathrm{CS}=$ constant spring,

$\mathrm{PS}=$ Pakse, $\mathrm{PPV}=$ positive predictive value, NPV=negative predictive value 
the range of $\mathrm{MCV}$ and $\mathrm{MCH}$ in patients without $\alpha$ thalassemia was 62.0-134.0 fL and 13.0-47.0 pg respectively. The lower level was detected in a thalassemia 1 patients at 60.0-86.0 fL and 19.0-28.0 pg for MCV and $\mathrm{MCH}$ respectively. The new cutoff value was estimated to be the highest MCV and $\mathrm{MCH}$ values of the patients with a thalassemia 1 gene plus one as $87 \mathrm{fL}$ and $29 \mathrm{pg}$, respectively. Efficiency of the new cutoff was calculated and results could increase specificity and PPV from $66.6 \%$ to $89.7 \%$ and $16.0 \%$ to $36.7 \%$ respectively (Figure 1).
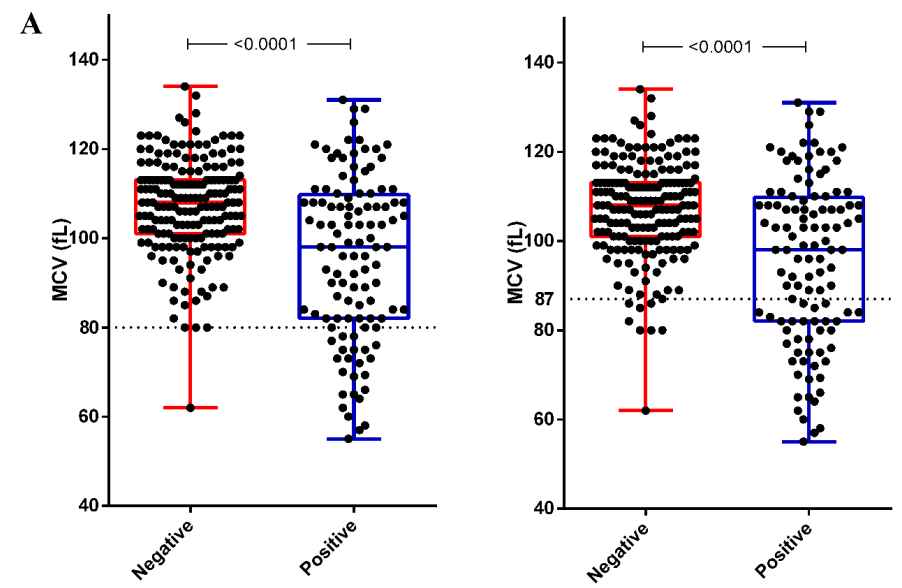

$\begin{array}{lrc} & \text { Percent } & \text { 95\% CI } \\ \text { Sensitivity } & \mathbf{1 0 0 . 0} \% & {[81.4 \%-100.0 \%} \\ \text { Specificity } & \mathbf{8 9 . 7 \%} & {[\mathbf{8 5 . 5} \%-\mathbf{9 3 . 0} \%]} \\ \text { PPV } & \mathbf{3 8 . 3} \% & {[30.5 \%-46.7 \%]} \\ \text { NPV } & \mathbf{1 0 0 . 0} \% & \end{array}$
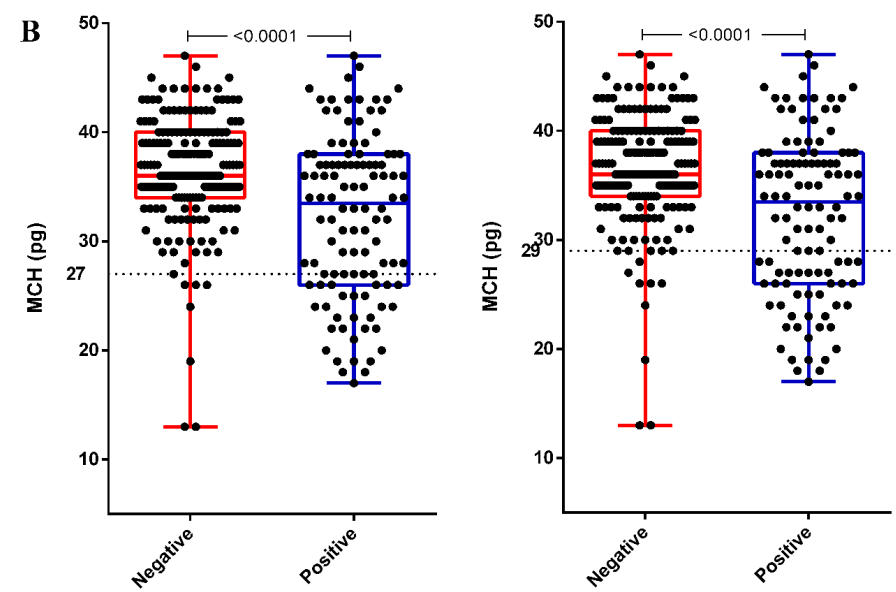

$\begin{array}{lrc} & \text { Percent } & 95 \% \text { CI } \\ \text { Sensitivity } & \mathbf{1 0 0 . 0} \% & {[81.4 \%-100.0 \%} \\ \text { Specificity } & \mathbf{8 9 . 0} \% & {[84.7 \%-92.4 \%]} \\ \text { PPV } & 36.7 \% & {[29.4 \%-44.7 \%]} \\ \text { NPV } & 100.0 \% & \end{array}$

Figure 1 Comparison between the old and the new cutoff values of mean corpuscular volume (MCV) and mean corpuscular hemoglobin $(\mathrm{MHC})$ between $\alpha$ thalassemia 1 and non-thalassemia 1 carrier

Old (left) and new (right) cutoff value of $\mathrm{MCV}(\mathrm{A})$ and $\mathrm{MCH}(\mathrm{B})$ were used to define patients with and without $\alpha$ thalassemia 1 gene. (A) the old cutoff value showed some false negative sample due to a higher MCV level after HIV infection. Increasing of MCV cutoff value from $80 \mathrm{fL}$ to $87 \mathrm{fL}$ helped enhance the sensitivity of the screening test, all patients with $\alpha$ thalassemia 1 gene were given a positive result. Also, a different of $\mathrm{MCH}$ between $\alpha$ thalassemia carrier and nonthalassemia carrier that could be used as screening criteria. Increasing of $\mathrm{MCH}$ cutoff from $27 \mathrm{pg}$ to 29 pg help increased screening efficiencies (B). 
The new cutoff values improved the efficiency of a thalassemia screening in HIV-1 infected patients, significantly. Next, we considered the efficiency of a thalassemia 1 screening if all methods were used together. The efficiency of screening power from 5 different methods comprising the OF test, MCV, MCH, MCV incorporated with $\mathrm{MCH}$, and $\mathrm{MCV}$ incorporated with $\mathrm{MCH}$ and the OF test were compared. Results showed the highest efficiencies when all tests were used together, cooperatively having sensitivity, specificity, PPV and NPV screening for HIV-1 infected patients of $100.0 \%, 92.5 \%$, $46.1 \%$ and $100.0 \%$ respectively (Table 4 ).

A diagram for $\alpha$ thalassemia 1 screening in HIV-1 infected patients is shown in Figure 2. This new cutoff can increase the accuracy of $\alpha$ thalassemia 1 screening in HIV-1 infected patients and also reduce false positive samples, resulting in the reduction of confirmation costs by DNA analyses.

\section{Discussion}

The data obtained revealed the differences in $\mathrm{Hb}$, Hct, and RBC may be partly due to the diverse RBC production of different sexes and ages. In addition, the reduction of these 3 factors may be either the result of an infection of hematopoietic stem cells by the HIV virus or an inhibitory effect through cytokine release by activated immune cells. There is a previous study that demonstrated an increase of Interleukin 18 and Stem Cell Factor in HIV-1 infected patient serum. ${ }^{17}$ These cytokines can induce lymphocyte production and drive CD34 positive stem cells to lymphoid progenitor cells instead of erythroid progenitor cells affecting $\mathrm{RBC}$ reduction. In addition, the reduced erythropoietin secretion in the elderly also causes changes in hematological data. ${ }^{18-20}$ However, not only the effect from the previous factors, there is evidence which demonstrated a physiological change to the elderly also contributes to a low $\mathrm{Hb}$ and Hct level. ${ }^{21}$ Taken together, these 3 parameters may alter the previous criteria for the diagnosis of $\alpha$ thalassemia 1 carrier.

Table 4 Efficiencies of a thalassemia 1 screening in human immunodeficiency virus infected patients using variety parameter combination

\begin{tabular}{llllll}
\hline Efficiencies index & OF (\%) & MCV 87 fL (\%) & MCH 29 pg (\%) & MCV+MCH (\%) & MCV+MCH+OF (\%) \\
\hline Sensitivity & 100.0 & 100.0 & 100.0 & 100.0 & 100.0 \\
Specificity & 66.6 & 89.7 & 89.0 & 89.0 & 92.5 \\
PPV & 16.0 & 38.3 & 36.7 & 36.7 & 46.1 \\
NPV & 100.0 & 100.0 & 100.0 & 100.0 & 100.0 \\
\hline
\end{tabular}

$\mathrm{OF}=$ osmotic fragility test, $\mathrm{MCV}=$ mean corpuscular volume, $\mathrm{MCH}=$ mean corpuscular hemoglobin, $\mathrm{PPV}=$ positive predictive value, $\mathrm{NPV}=$ negative predictive value 


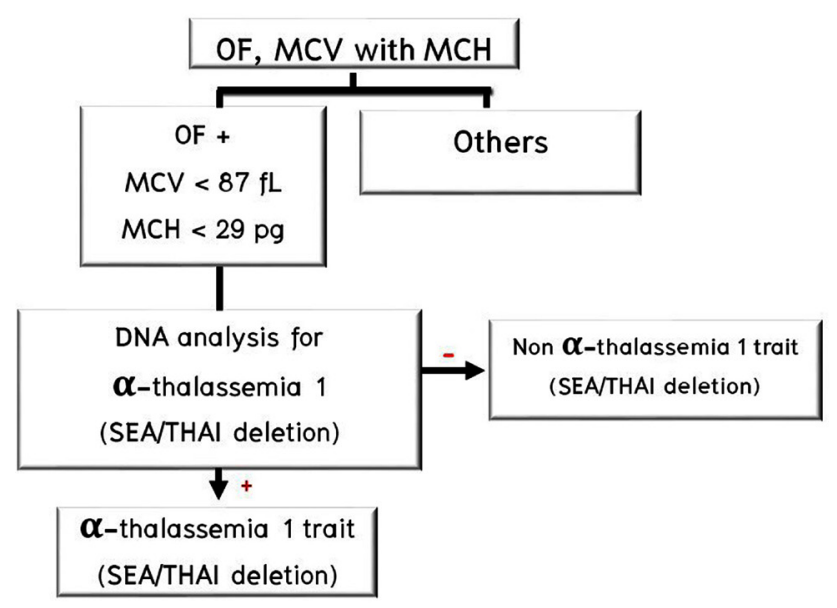

Figure 2 Improvement of $\alpha$ thalassemia screening scheme in human immunodeficiency virus infected patients.

OF test, MCV, and MCH have been used cooperatively in a thalassemia screening in HIV-1 infected patients. The sample with OF positive, MCV less than $87 \mathrm{fL}$ and $\mathrm{MCH}$ less than $29 \mathrm{pg}$ were defined as screening positive for $\alpha$ thalassemia 1. In contrast, any patients does not confine to the criteria was defined as screening negative for $\alpha$ thalassemia 1.

Our results show that the changes of these parameters affect a thalassemia screening using the OFtest, $\mathrm{MCV}$, and $\mathrm{MCH}$. The low screening efficiencies of the OF test may be a reflection of the side effects of the antiviral drugs and HIV-1 virus itself. ${ }^{19,22,23}$ And these could interfere with mineral absorption and result in changes of cell protein synthesis and reduced fatty acid on the cell membrane. The consequences may increase the rigidity in RBC's infected patients, resulting in false positives. ${ }^{24}$ Recently, Quiros-Roldan and colleagues demonstrated that inflammation cytokines, such as IL-6 and $\mathrm{IL}-8$, are correlated with low $\mathrm{Hb}$ levels in HIV-1 infected patients. Therefore, these may lead to false positives in OF screening, due to a lower $\mathrm{Hb}$ content in red blood cells. ${ }^{22}$

Interestingly, the new cutoff values for MCV and $\mathrm{MCH}$ in our findings were higher than the conventional ones. This is a concern due to the increase of MCV and $\mathrm{MCH}$ in HIV infected patients. Some evidence suggests that the antiviral drug is another factor involved in the change of lipid levels in the patients. Increasing the highdensity lipid cholesterol significantly correlates with the $\mathrm{MCV}$ in the patients with azidothymidine therapy. ${ }^{21}$ Other evidence indicated that HIV infected patients showed defects in vitamin B12 and folate metabolism, causing the impairment of DNA synthesis, thus resulting in megaloblastic changes in red blood cells. ${ }^{24-26}$ These new cutoff values help increase the specificity and PPV of the screening test. The higher specificity and PPV lead to more trustworthiness of the screening process, and it is suggested that HIV-1 infected patients who are given the positive results by this screening method have more chance to be a thalassemia 1 carriers than with the previous screening method.

\section{Conclusion}

a thalassemia 1 screening using the OF test and $\mathrm{MCV}$ and $\mathrm{MCH}$ with the old cutoff values at $80 \mathrm{fL}$ and $27 \mathrm{pg}$ indicated low screening efficiencies for HIV-1 
infected patients. The new cutoff values for MCV and $\mathrm{MCH}$ were, therefore, determined to improve $\alpha$ thalassemia 1 screening efficiencies in HIV-1 infected patients. The incorporation of the $\mathrm{OF}$ test with the new cutoff of $\mathrm{MCV}$ and $\mathrm{MCH}$ improved screening efficiencies and reduced false positive results in a thalassemia 1 screening in $\mathrm{HIV}-1$ infected patients.

\section{Acknowledgement}

This research was supported by a grant from the National Research Council of Thailand, University of Phayao (RD59068).

\section{References}

1. Cappellini MD, Cohen A, Eleftheriou A, Piga A, Porter J, Tahr A. Genetic basis and pathophysiology. In: Cappellini MD Guidelines for the clinical management of thalassaemia. $2^{\text {nd }}$ ed. Nicosia (CY): Thalassaemia International Federation; 2008;p.14-26.

2. Yang Y, Li DZ. Early onset of fetal hydrops associated with the alpha-thalassemia - -(THAl) deletion. Hemoglobin 2014; 38:431-4.

3. Li DZ, Liao C, Li J, Xie XM, Huang YN, Wu QC. Hemoglobin $\mathrm{H}$ hydrops fetalis syndrome resulting from the association of the - -SEA deletion and the alpha Quong Szealpha mutation in a Chinese woman. Eur J Haematol 2005;75:25961.

4. Harteveld CL, Higgs DR. a-thalassaemia. Orphanet J Rare Dis $2010 ; 5: 1-21$

5. Tongsong $T$, Wanapirak C, Sirivatanapa $P$, Sanguansermsri T, Sirichotiyakul S, Piyamongkol W, et al. Prenatal control of severe thalassaemia: Chiang Mai strategy. Prenat Diagn 2000;20:229-34.

6. Maccioni L, Cao A. Osmotic fragility test in heterozygotes for alpha and beta thalassaemia. J Med Genet 1985;22:374-6.

7. Tangvarasittichai $\mathrm{O}$, Poonanan N, Tangvarasittichai S. Using red cell indices and reticulocyte parameters for carrier screening of various thalassemia syndromes. Indian J Clin Biochem 2017;32:61-7.

8. Panyasai S, Saning R, Nooklieng L, Budiah H. Preliminary study of stability of blood used in the one tube osmotic fragility test to screen severe thalassemia carriers. Bull Chiang Mai Assoc Med Sci 2008;41:94-102.

9. United Nations programme on HIV/AIDS (UNAIDS). UNAIDS DATA 2017 [homepage on Internet]. Geneva: UNAIDS; 2017 [cited 2018 Apr 10]. Available from: http://www. unaids.org/sites/default/files/media_asset/20170720_ Data_book_2017_en.pdf

10. Thisyakorn U. Elimination of mother-to-child transmission of HIV: lessons learned from success in Thailand. Paediatr Int Child Health 2017;37:99-108.

11. Patwardhan MS, Golwilkar AS, Abhyankar JR, Atre MC. Hematological profile of HIV positive patients. Indian J Pathol Microbiol 2002;45:147-50

12. Okeke CO, Amilo Gl, Ifeanyichukwu M, Ochiabuto OMTB, Onyemelukwe AO, Ibekailo SN. Effect of HIV infection and antiretroviral therapy duration on reticulocyte count and red cell indices. Int Blood Res Rev 2014;2:187-97.

13. Eyer-Silva WA, Arabe J, Pinto JF, Morais-De-Sa CA. Macrocytosis in patients on stavudine. Scand J Infect Dis 2001;33: 239-40.

14. Athanassiou GA, Moutzouri AG, Gogos CA, Skoutelis AT. Red blood cell deformability in patients with human immunodeficiency virus infection. Eur J Clin Microbiol Infect Dis 2010;29:845-9.

15. Sae-ung N, Fucharoen G, Sanchaisuriya K, Fucharoen S. Alpha(0)-thalassemia and related disorders in northeast Thailand: a molecular and hematological characterization. Acta Haematol 2007;117:78-82.

16. Fucharoen S, Sanchaisuriya K, Fucharoen G, Panyasai S, Devenish R, Luy L. Interaction of hemoglobin $E$ and several forms of alpha-thalassemia in Cambodian families. Haematologica 2003;88:1092-8.

17. Bordoni V, Viola D, Sacchi A, Pinnetti C, Casetti R, Cimini E, et al. IL-18 and stem cell factor affect hematopoietic progenitor cells in HIV-infected patients treated during primary HIV infection. Cytokine 2018;103:34-7.

18. Makipour S, Kanapuru B, Ershler WB. Unexplained anemia in the elderly. Semin Hematol 2008;45:250-4.

19. Zauli G, Re MC, Visani G, Furlini G, Mazza P, Vignoli M, et al. Evidence for a human immunodeficiency virus type 1-mediated suppression of uninfected hematopoietic (CD34+) cells in AIDS patients. J Infect Dis 1992;166:710-6. 
20. Bordoni V, Bibas M, Viola D, Sacchi A, Cimini E, Tumino N, et al. Bone marrow CD34+ progenitor cells from HIV-infected patients show an impaired $\mathrm{T}$ cell differentiation potential related to proinflammatory cytokines. AIDS Res Hum Retroviruses 2017;33:590-6.

21. Eisenstaedt R, Penninx BW, Woodman RC. Anemia in the elderly: current understanding and emerging concepts. Blood Rev 2006;20:213-26.

22. Quiros-Roldan E, Castelli F, Lanza P, Pezzoli C, Vezzoli M, Biasiotto G, et al. The impact of antiretroviral therapy on iron homeostasis and inflammation markers in HIV-infected patients with mild anemia. J Transl Med 2017;15:256.

23. Kim AH, Jang W, Kim Y, Park YJ, Han K, Oh EJ. Mean corpuscular volume $(\mathrm{MCV})$ values reflect therapeutic effectiveness in zidovudine-receiving HIV patients. J Clin Lab Anal 2013;27: 373-8.

24. Cooper RA. Influence of increased membrane cholesterol on membrane fluidity and cell function in human red blood cells. J Supramol Struct 1978;8:413-30.

25. Oliveira OC, Oliveira RA, Souza Ldo R. Impact of antiretroviral therapy on occurrences of macrocytosis in patients with HIV/AIDS in Maringa, State of Parana. Rev Soc Bras Med Trop 2011;44:35-9.

26. Moyle G, Sawyer W, Law M, Amin J, Hill A. Changes in hematologic parameters and efficacy of thymidine analoguebased, highly active antiretroviral therapy: a meta-analysis of six prospective, randomized, comparative studies. Clin Ther 2004;26:92-7. 